\title{
Martensite Formation from Reverted Austenite at Sub-zero Celsius Temperature
}

Nießen, Frank; Villa, Matteo; Somers, Marcel A. J.

Published in:

Metallurgical and Materials Transactions A: Physical Metallurgy and Materials Science

Link to article, DOI:

$10.1007 / \mathrm{s} 11661-018-4887-6$

Publication date:

2018

Document Version

Peer reviewed version

Link back to DTU Orbit

Citation (APA):

Nießen, F., Villa, M., \& Somers, M. A. J. (2018). Martensite Formation from Reverted Austenite at Sub-zero Celsius Temperature. Metallurgical and Materials Transactions A: Physical Metallurgy and Materials Science, $49 A(11), 5241-5245$. https://doi.org/10.1007/s11661-018-4887-6

\section{General rights}

Copyright and moral rights for the publications made accessible in the public portal are retained by the authors and/or other copyright owners and it is a condition of accessing publications that users recognise and abide by the legal requirements associated with these rights.

- Users may download and print one copy of any publication from the public portal for the purpose of private study or research.

- You may not further distribute the material or use it for any profit-making activity or commercial gain

- You may freely distribute the URL identifying the publication in the public portal 


\section{Abstract}

\title{
Martensite formation from reverted austenite at sub-zero Celsius temperature
}

\author{
F. Niessen ${ }^{1, a^{*}}$, M. Villa ${ }^{2, b}$, M. A. J. Somers ${ }^{2, c}$ \\ ${ }^{1}$ Technical University of Denmark, Danish Hydrocarbon Research and Technology Centre, 2800 \\ Kgs. Lyngby, Denmark \\ ${ }^{2}$ Technical University of Denmark, Department of Mechanical Engineering, 2800 Kgs. Lyngby, \\ Denmark \\ acontact@fniessen.com; ${ }^{\mathrm{a}}$ matv@mek.dtu.dk; c somers@mek.dtu.dk
}

Inter-critical annealing of soft martensitic stainless steel leads to formation of fine-grained reverted austenite, which is stabilized by partitioning of Ni. Generally it is reported that the fraction of reverted austenite is not affected by immersion in cryogenic liquids, such as boiling $\mathrm{N}_{2}$ and He. Present data shows that, despite its apparent stability at boiling nitrogen temperature, reverted austenite transforms to isothermal (thermally activated) martensite during holding at $195 \mathrm{~K}$.

Keywords: steel; reverted austenite; cryogenic treatment; martensite formation

\footnotetext{
*Corresponding author, currently with Technical University of Denmark, Department of Mechanical Engineering, 2800 Kgs. Lyngby, Denmark
} 
1 Soft martensitic stainless steels are essentially Fe-Cr-Ni alloys which contain a very low fraction of

2 interstitially dissolved $\mathrm{C}$ and $\mathrm{N}$ [1-3]. These steels are used for heavy-section water turbine

3 components, pump and valve bodies and wellhead equipment in the oil and gas industry [4]. Soft

4 martensitic stainless steels are known for their resistance against $\mathrm{CO}_{2}$ corrosion, good weldability, good

5 ductility at high strength and excellent impact toughness, even at sub-zero Celsius temperatures $[5,6]$.

6 As for the case of supermartensitic stainless steels [1] and ferritic Fe-Ni alloys [7], the excellent

7 impact toughness at low temperature is partially owed to the low content of interstitials, which leads to

8 low hardness [1], and partially to the presence of, so called, reverted austenite, which forms a fine

9 “composite” microstructure with tempered martensite [7-9]. Soft martensitic stainless steels show

10 impact values of approx. 70-110 J at $190 \mathrm{~K}$ [5,6,10]; supermartensitic stainless steels even in excess of

$11100 \mathrm{~J}$ [1,2,11]. Consequently, these materials appear particularly suitable for sub-zero Celsius

12 applications $[1,5,6,12]$.

13 Reverted austenite forms during inter-critical annealing treatment between $A_{1}$ and $A_{3}$, where both

14 ferrite and austenite can co-exist under thermodynamic equilibrium conditions. After austenitization 15 and cooling to room temperature, the microstructure consists of lath martensite; heating to and 16 annealing within the inter-critical temperature region promotes partial reversion of martensite to 17 austenite in the form of austenite films at martensite lath boundaries [13]. Austenite formation is 18 accompanied by the partitioning of alloying elements in an attempt to establish thermodynamic 19 equilibrium. In particular the diffusion-controlled $\mathrm{Ni}$ partitioning governs the overall kinetics of the 20 transformation [14,15]. Because of the partitioning of alloying elements, reverted austenite is more 21 stable than the homogeneous austenite formed during austenitization and can be retained at room 22 temperature $[8,15,16]$. 
The material used in the present work is a $15 \mathrm{Cr}-5.8 \mathrm{Ni}-1 \mathrm{Mo}-0.9 \mathrm{Mn}$ steel (in wt-\%), grade EN

2 1.4418. The content of interstitials was 0.034 wt.\% C and 0.032 wt.\% N, respectively. The formation of

3 reverted austenite is presented in Fig. 1. The initial “as normalized” condition (i.e. austenitized and

4 quenched) was obtained by austenitization at $1190 \mathrm{~K}$ for $0.6 \mathrm{ks}$ and quenching at an average rate of

5 approx. $1 \mathrm{~K}^{-\mathrm{s}^{-1}}$. Subsequent intercritical annealing consisted in heating to a temperature in the range

$6 \quad$ 898-973 K, followed by cooling to room temperature. The heating rate was constant and equal to 0.25

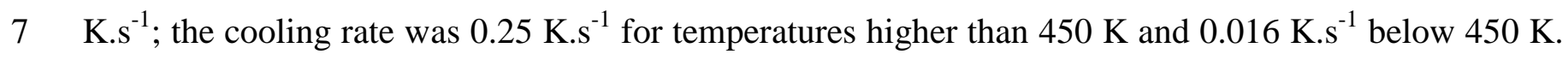

8 Intercritical annealing was carried out at the HZB-Bessy II synchrotron facility, EDDI-beamline [17],

9 and the fractions of austenite and martensite were determined in situ by X-ray diffraction (XRD) (c.f.

10 Ref. [18] for details).

11 Fig. 1 shows that the material is essentially martensitic after normalization and contains less than 3

12 vol.\% of retained austenite. $\mathrm{A}_{\mathrm{c} 1}$ is approx. $840 \mathrm{~K}$ and on continuous heating, the transformation

13 accelerates such that the fraction of austenite reaches approx. 0.5 at $973 \mathrm{~K}$, the highest applied

14 annealing temperature. On cooling, additional formation of austenite occurs at temperatures higher than

$15 \mathrm{~A}_{\mathrm{c} 1}$. No further change in the phase fraction is measured on continuous cooling to room temperature for

16 the samples treated to $898 \mathrm{~K}$ and $923 \mathrm{~K}$; for cooling from 948 and $973 \mathrm{~K}$ reverted austenite partially

17 transforms into martensite. In all cases inter-critical treatment yields a significant fraction of reverted 18 austenite.

19 It was demonstrated in Ref. [19] that the impact toughness of the present steel grade scales with

20 the fraction of reverted austenite. This relation naturally raises the question whether reverted austenite

21 is unconditionally thermally stable at sub-zero Celsius temperatures. The driving force for martensite

22 formation increases with undercooling below $\mathrm{T}_{0}$ [20], suggesting that lowering the temperature is a 


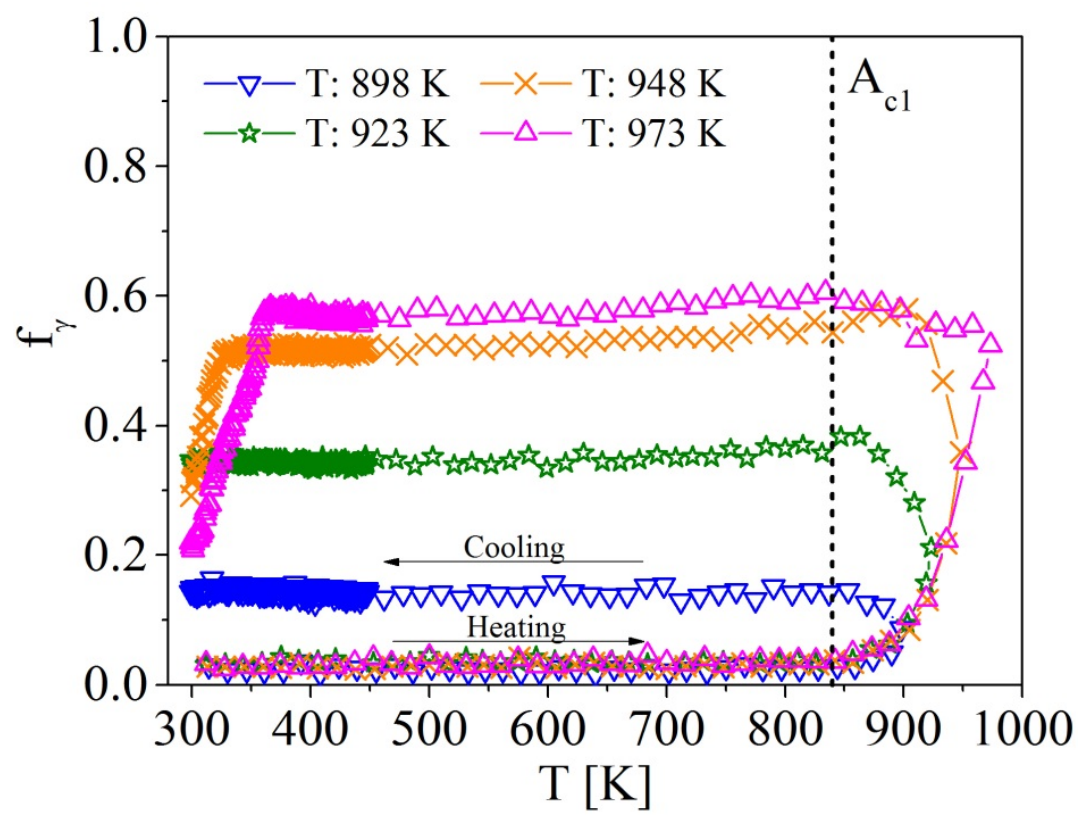

Figure 1. Fraction of austenite $\mathbf{f}_{\gamma}$ versus temperature $T$ for four inter-critical annealing treatments. Numbers in the legend refer to the temperature reached during the heating step, immediately followed by cooling.

1 viable method to test thermal stability. Several groups have claimed that the phase fraction of reverted 2 austenite in various soft and supermartensitic stainless steels is not affected by immersion in boiling $\mathrm{N}_{2}$ $3 \quad$ (77 K) [5,6,11,21-23] or boiling He (4 K) [10]. Niederau [5], Grounes and Rao [6] and Kulmburg et al. [23] claimed thermal stability of 5 reverted austenite during immersion in boiling $\mathrm{N}_{2}$ without providing experimental evidence. Song et 6 al. [10] and Carrouge et al. [21] provided X-ray diffractograms before and after immersion in boiling

7 He and $\mathrm{N}_{2}$, respectively, which did not indicate a change in phase fraction. Bilmes et al. [11] applied

8 Mössbauer spectroscopy to compare the fraction of reverted austenite after isothermal holding at 271

9 K, $256 \mathrm{~K}, 248 \mathrm{~K}$ and $77 \mathrm{~K}$ for $72 \mathrm{ks}$ and concluded that austenite is stable. Finally, Bojack et al. [22] applied magnetometry to show that no transformation occurs after $72 \mathrm{ks}$ at boiling $\mathrm{N}_{2}$ temperature and 11 anticipated that reverted austenite remains stable after sub-zero Celsius treatment if no martensite is 
Table 1. Overview of materials, annealing parameters and testing procedures considered in previous works in order to test the thermal stability of reverted austenite in soft martensitic and supermartensitic stainless steels.

\section{Ref. Approx. composition [wt.\%]}

Annealing treatment

Cryogenic treatment

[6] Cr 13-16, Ni 5-6, Mo <1.5, C 0.03-0.06 $860 \mathrm{~K}$ $77 \mathrm{~K}$

[23] Cr 12-17, Ni 4-7, Mo <2.5, C 0.03 Not specified $77 \mathrm{~K}$

[5] Cr 15-17, Ni 4.5-6.5, Mo <2.9, C: $<0.07$ $870 \mathrm{~K} / 28.8 \mathrm{ks}$ $77 \mathrm{~K}$

[11] Cr 12, Ni 5.4, Mo 0.5, C 0.028 $870 \mathrm{~K} / 7.2 \mathrm{ks}$ 271 K, 256 K, 248 K, 77 K / 72 ks

[21] Cr 12, Ni 6.5, Mo 2.5, C 0.01 $910 \mathrm{~K}$ $77 \mathrm{~K} / 3.6 \mathrm{ks}$

[10] Cr 12, Ni 4.4, Mo 0.5, C 0.07 $870 \mathrm{~K} / 14.4 \mathrm{ks}$ $4 \mathrm{~K}$

[22] Cr 12, Ni 5.6, Mo 2.0, C 0.02 $908 \mathrm{~K} / 14.4 \mathrm{ks}$ $77 \mathrm{~K} / 72 \mathrm{ks}$

1 formed during cooling to room temperature after inter-critical annealing. An overview of literature data 2 is given in Table 1.

In the current work, we applied vibrating sample magnetometry (VSM) on cylindrical samples

4 of $Ø 3 \times 0.75 \mathrm{~mm}$ to test the thermal stability of reverted austenite. Heat treatment conditions were 5 consistent with those applied in in-situ XRD, apart from the cooling rate from the intercritical 6 annealing temperature, which was not constant and significantly faster than for the XRD investigation.

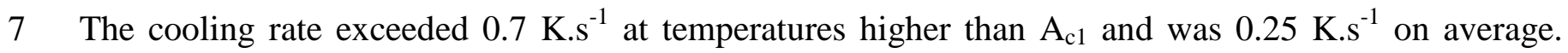

8 After inter-critical annealing, the material was stored at room temperature for approx. 1 year. 
2 SuperTran-VP continuous flow cryostat and was applied before subjecting the material to sub-zero

3 Celsius treatment and after immersion in boiling $\mathrm{N}_{2}$ followed by fast re-heating by immersion in water

4 (up-quenching). The magnetic properties were evaluated at $290 \mathrm{~K}$ by recording of hysteresis curves.

5 Three repetitions were applied for evaluation of the experimental error. The fraction of austenite was

6 determined by comparison of the specific magnetic moment at saturation of the samples, $M^{\text {sat }}$,

7 evaluated at 1 Tesla with the one of the normalized sample, $M_{r e f}^{\text {sat }}$, taking into account the initial

8 fraction of retained austenite, $f_{\gamma_{r e t}}$, as measured by XRD (i.e. 0.03):

9

$$
f_{\gamma}=1-f_{\alpha^{\prime}}=1-\frac{M^{s a t}}{M_{r e f}^{s a t}\left(1-f_{\gamma_{r e t}}\right)}
$$

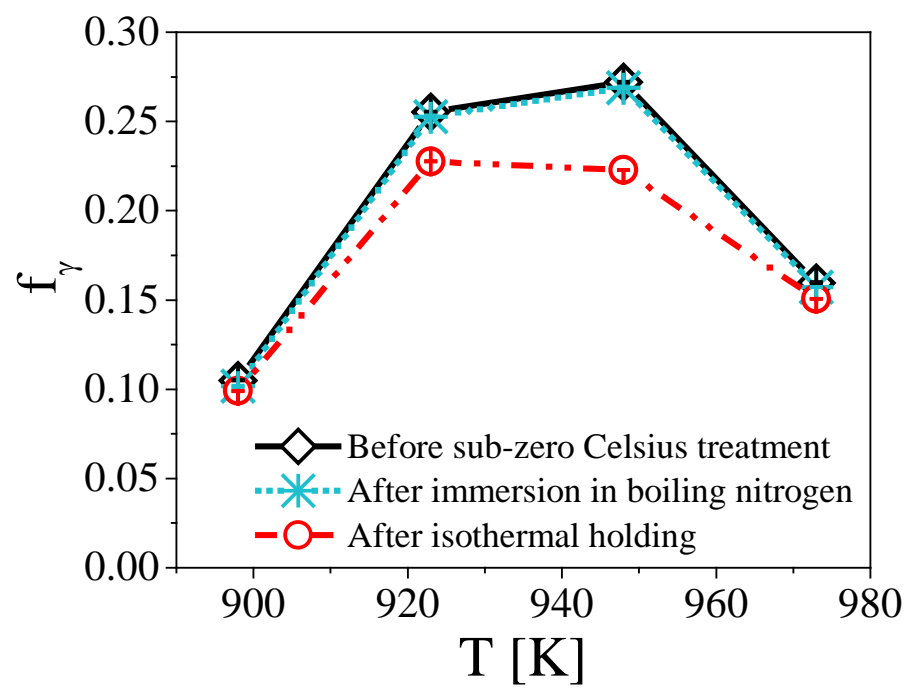

Figure 2. Fraction of austenite $f_{\gamma}$ versus annealing temperature $T$. The three data sets refer to the material before sub-zero Celsius treatment, after immersion in boiling $N_{2}$ for $0.3 \mathrm{ks}$ and after additional isothermal holding at 195 K for $15.3 \mathrm{ks.}$ 
Table 2. Measured austenite fraction, $f_{\gamma}$, in vol.\% of differently annealed samples during or after applied thermal cycles in XRD or VSM

\begin{tabular}{cccccc} 
Thermal cycle & Method & $\boldsymbol{f}_{\boldsymbol{\gamma}}(\mathbf{8 7 3} \mathbf{K})$ & $\boldsymbol{f}_{\boldsymbol{\gamma}}(\mathbf{8 9 8} \mathbf{K})$ & $\boldsymbol{f}_{\boldsymbol{\gamma}}(\mathbf{9 2 3} \mathbf{K})$ & $\boldsymbol{f}_{\boldsymbol{\gamma}}(\mathbf{9 4 8} \mathbf{~ K})$ \\
\hline $\begin{array}{c}\text { Intercritical annealing } \\
\text { (maximum fraction during annealing) }\end{array}$ & XRD & 0.15 & 0.38 & 0.58 & 0.61 \\
\hline $\begin{array}{c}\text { Intercritical annealing } \\
\text { (retained fraction at room temperature) }\end{array}$ & XRD & 0.15 & 0.35 & 0.29 & 0.21 \\
\hline $\begin{array}{c}\text { Intercritical annealing } \\
\text { (retained fraction at room temperature) }\end{array}$ & VSM & 0.10 & 0.26 & 0.27 & 0.16 \\
\hline $\begin{array}{c}\text { Immersion in } N_{2} \\
\text { (retained fraction at room temperature) }\end{array}$ & VSM & 0.10 & 0.25 & 0.27 & 0.16 \\
\hline $\begin{array}{c}\text { Sub-zero treatment } \\
\text { (retained fraction at room temperature) }\end{array}$ & VSM & 0.10 & 0.23 & 0.22 & 0.15 \\
\hline
\end{tabular}

Fig. 2 displays and Table 2 lists the results of the investigations. The content of austenite before

2 sub-zero Celsius cooling is comparable, but not identical, to the austenite fractions obtained by in-situ

3 synchrotron investigation (cf. Fig. 1). Immersion in boiling nitrogen and up-quenching to room

4 temperature did not significantly affect the fraction of austenite, which is consistent with literature data

5 (cf. Table 1) and suggests thermal stability of reverted austenite in soft martensitic stainless steel at low

6 temperatures.

Recently, it was discussed that the formation of lath martensite at sub-zero temperature requires

8 thermal activation and should be approached by Time Temperature Transformation (TTT)

9 diagrams [24-29]. A schematic representation is given in Fig. 3 (cf. [25]). According to such

10 diagrams isothermal martensite formation proceeds at a maximum rate at a temperature appreciably

11 higher than $80 \mathrm{~K}$ and proceeds only very slowly for temperatures just below $273 \mathrm{~K}$. As Fig. 3

12 illustrates, martensite formation can be suppressed for fast cooling to $80 \mathrm{~K}$. For continuous heating 


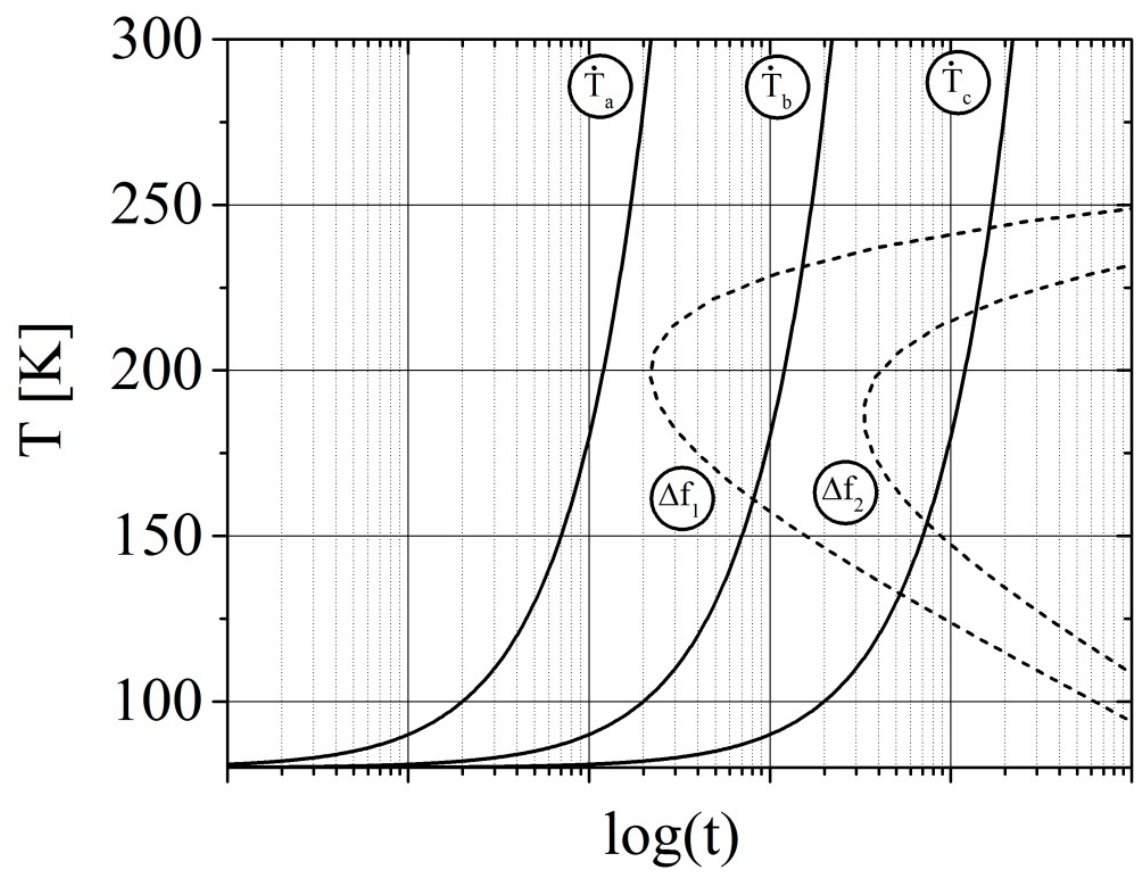

Figure 3. Schematic Time-Temperature-Transformation, TTT, diagram for formation of lath martensite from an approximate austenite fraction of 100 vol.\% (after [25]). The solid lines correspond to time-temperature curves, starting from an initial temperature of $80 \mathrm{~K}$ and following linear heating rates, $\dot{T}_{a}>\dot{T}_{b}>\dot{T}_{c}$. The broken lines indicate constant fractions of transformed martensite, $\Delta f_{2}>\Delta f_{1}$, during isothermal holding. The diagram demonstrates that up-quenching can prevent martensite formation (following $\dot{T}_{a}$ ) and that the martensite content formed on reaching room temperature depends on the heating rate (comparing $\dot{T}_{b}$ and $\dot{T}_{c}$ ).

1 from $80 \mathrm{~K}$, martensite formation is suppressed for relatively fast linear heating (curve $\dot{T}_{a}$ ), while slower

2 heating (curves $\dot{T}_{b}$ and $\dot{T}_{c}$ ) promotes the formation of martensite. At present there is insufficient 3 information to conclude about the rate-controlling mechanism for formation of lath 4 martensite $[26,28,29]$.

Evidently, Fig. 3 suggests that reverted austenite may appear stable in soft martensitic stainless

6 steel and that it depends on the heating rate to room temperature whether any martensite formation is

7 observed. This is no guarantee that austenite is stable at an intermediate sub-zero Celsius temperature. 
1 In order to test this hypothesis, the same samples subjected to VSM investigation before and after

2 boiling nitrogen were subjected to an additional sub-zero Celsius treatment. The thermal cycle

3 consisted of cooling at $0.25 \mathrm{~K} . \mathrm{s}^{-1}$ from $290 \mathrm{~K}$ to $195 \mathrm{~K}$, isothermal holding at $195 \mathrm{~K}$ for $15.3 \mathrm{ks}$ and

4 heating at $0.25 \mathrm{~K} . \mathrm{s}^{-1}$ to $290 \mathrm{~K}$. VSM was applied to monitor the evolution of magnetization at

5 saturation in the cycle, applying a constant magnetic field of 1 T. Additionally, the magnetic properties

6 were tested at the end of the thermal cycle as for the other two conditions (i.e. not treated and after

7 immersion in boiling nitrogen). Fig. 4 shows that the additional thermal cycle reduced the austenite

8 content by up to 5 vol.\% austenite. In particular the reverted austenite formed at 923 and $948 \mathrm{~K}$ was

9 affected by the cryogenic cycle. In-situ measurement of the austenite fraction during cryogenic

10 treatment revealed that no considerable transformation occurred during heating and cooling (Fig. 4a),

11 and that the rate of martensite formation during isothermal holding followed an exponential decay (Fig.

12 4b). The isothermal curves for the 923 and $948 \mathrm{~K}$ conditions indicate that the transformation would
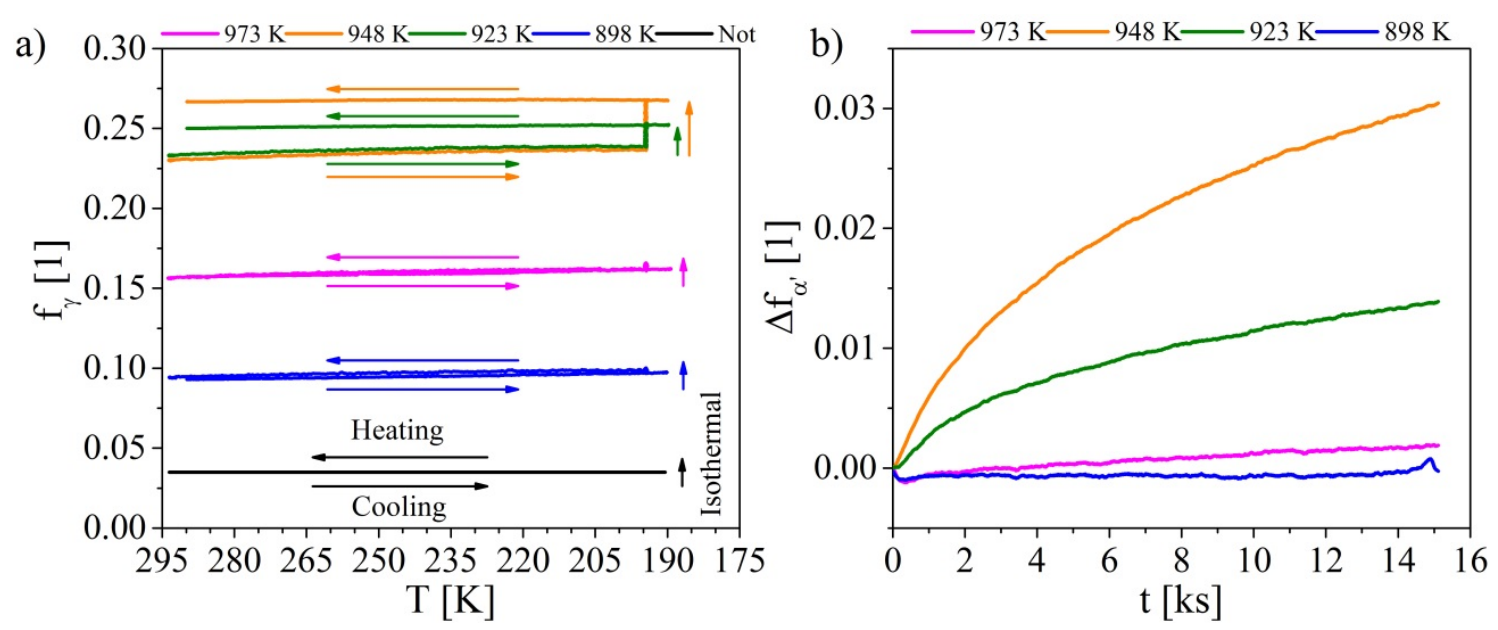

Figure 4. VSM results from of sub-zero Celsius treatment: (a) Fraction of austenite, $\boldsymbol{f}_{\gamma}$, of the differently tempered

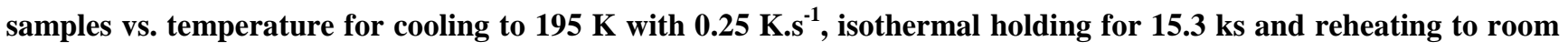

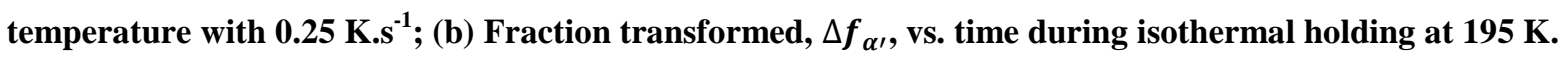


1 continue if further holding was applied.

2

3

4 5

The present results demonstrate that the common procedure to validate the thermal stability of reverted austenite, i.e. immersion into liquids at $77 \mathrm{~K}$ or lower temperature, is not a sufficient proof for the stability of reverted austenite against martensite formation. With reference to the schematic TTT diagram in Fig. 3, the testing temperatures in research published so far (Table 1) were chosen too low, such that martensite formation was suppressed and proceeded only very slowly [5,6,10,11,21-23] and heating rates could have been too fast. Bilmes et al. [11] considered higher temperatures in the range of $271-248 \mathrm{~K}$ to test thermal stability of reverted austenite, which are likely to be too high to build up a sufficient driving force for martensite formation.

Based on the generally observed kinetics of isothermal martensite formation in the literature $[25,28,29]$ and the specific results obtained on reverted austenite in the present work, we suggest isothermal holding for several 10 ks (i.e. several days) at $195 \mathrm{~K}$ (frozen $\mathrm{CO}_{2}$ temperature) as a test for the thermal stability of austenite.

The most effective temperature region for isothermal martensite formation, approx. $180-210$ $\mathrm{K}$, is often used to measure the impact toughness at sub-zero Celsius temperature $[1,5,6,10,11,21,30,31]$. The demonstrated possibility of isothermal martensite formation in this temperature region could enable a time dependent change in impact toughness. Consequently, we propose to state the cooling time of samples, similar to the conventional statement of annealing times of heat-treated samples, when reporting impact toughness values. Further, impact testing for qualification of metastable austenite containing steels should be carried out on samples which were exposed to different cryogenic holding times in the temperature region around $195 \mathrm{~K}$. 
In summary, it was demonstrated that reverted austenite which is stable at room temperature

2 after inter-critical annealing, is also thermally stable during immersion in boiling $\mathrm{N}_{2}$, but could partially

3 be transformed to martensite during holding at an intermediate temperature of $195 \mathrm{~K}$. Up till now,

4 several tests in the literature at boiling $\mathrm{N}_{2}$ or He temperature were considered proof that reverted

5 austenite remains stable during sub-zero Celsius application. Relatively fast transformation at $195 \mathrm{~K}$

6 and negligible transformation at $\mathrm{T}<120 \mathrm{~K}$ can be understood in terms of thermally activated martensite

7 formation as displayed by C-curves in TTT diagrams in the sub-zero Celsius range. The present results

8 indicate that impact toughness measured at sub-zero Celsius temperatures can be time dependent, as it

9 directly correlates with the fraction of austenite.

\section{Acknowledgement}

11 Mikkel F. Hansen is acknowledged for providing the VSM facilities. The Danish Underground

12 Consortium is gratefully acknowledged for financial support to the Danish Hydrocarbon Research

13 Center (DHRTC), which partly financed this work. This work was financially supported by the Danish

14 Council for Independent Research [grant number: DFF-4005-00223]. 


\section{References}

2 [1] A.W. Marshall and J.C.M. Farrar: Weld. World, 2001, vol. 45, pp. 19-42.

3 [2] K. Kondo, M. Ueda, K. Ogawa, H. Hirata, H. Takabe, and Y. Miyazaki: in Supermartensitic Stainl. Steels 1999, 1999, pp. 11-18.

5 [3] F. Niessen: Mater. Sci. Technol., 2018, vol. 0836, pp. 1-14.

6 [4] L.M. Smith and M. Celant: in Supermartensitic Stainl. Steels 1999, 1999, pp. 66-73.

7 [5] H.J. Niederau: Zeitschrift Des Vereins Dtsch. Ingenieure Für Maschinenbau Und Met. Eig., 1982, vol. 21, pp. 801-8.

9 [6] M. Grounes and S. Rao: Trans. ASM, 1969, vol. 62, pp. 902-14.

10 [7] J.W. Morris Jr.: in Encycl. Adv. Mater., H.D. McPerson, ed., Pergamon Press, Oxford, UK, 111986.

12 [8] S. Zhang, P. Wang, D. Li, and Y. Li: Mater. Des., 2015, vol. 84, pp. 385-94.

13 [9] Y. Iwabuchi and S. Sawada: Stainl. Steel, 1982, pp. 332-54.

14 [10] Y. Song, D.H. Ping, F.X. Yin, X.Y. Li, and Y.Y. Li: Mater. Sci. Eng. A, 2010, vol. 527, 15 pp. 614-18.

16 [11] P.D. Bilmes, M Solari, and C.L. Llorente: Mater. Charact., 2001, vol. 46, pp. 285-96.

17 [12] H.J. Niederau: in Stainl. Steel Cast., G. Behal and A.S. Melilli, eds., ASTM, Bal Harbour, 18 Florida, 1982, pp. 382-93.

[13] F. Niessen, F. B. Grumsen, J. Hald, and M. A. J. Somers: in Proc. 24th IFHTSE Congr., 2017, 20 pp. 138-45.

21 [14] F. Niessen, M. Villa, J. Hald, and M.A.J. Somers: Mater. Des., 2017, vol. 116, pp. 8-15.

22 [15] J. D. Escobar, J. D. Poplawsky, G. A. Faria, J. Rodriguez, J. P. Oliveira, C. A.F. Salvador, P. R. 
Mei, S. S. Babu, and A. J. Ramirez: Mater. Des., 2018, vol. 140, pp. 95-105.

[16] N. Nakada, T. Tsuchiyama, S. Takaki, and N. Miyano: ISIJ Int., 2011, vol. 51, pp. 299-304.

[17] C. Genzel, I. Denks, and M. Klaus: Mater. Sci. Forum, 2006, vol. 524-525, pp. 193-98.

[18] F. Niessen, M. Villa, D. Apel, O. Keßler, M. Reich, J. Hald, and M.A.J. Somers: Mater. Sci. Forum, 2017, vol. 879, pp. 1381-86.

[19] M. Wiessner, E. Gamsjäger, S. van der Zwaag, and P. Angerer: Mater. Sci. Eng. A, 2017, vol. 682, pp. 117-25.

[20] C. Zener: AIMME, Met. Technol., 1946, pp. 550-95.

[21] D. Carrouge, H.K.D.H. Bhadeshia, and P. Woollin: Sci. Technol. Weld. Join., 2004, vol. 9, pp. 377-89.

[22] A. Bojack, L. Zhao, P. F. Morris, and J. Sietsma: Metall. Mater. Trans. A Phys. Metall. Mater. Sci., 2014, vol. 45, pp. 5956-67.

[23] A. Kulmburg, F. Konrtheuer, M. Koren, O. Gründler, K. Hutterer, and Kapfenberg: Berg- Und Hüttenmännische Monatshefte, 1981, vol. 123, pp. 104-8.

[24] Ji Cheng Zhao and Michael R. Notis: Mater. Sci. Eng. R, 1995, vol. 15, pp. 135-207.

[25] M. Villa, M.F. Hansen, and M.A.J. Somers: Scr. Mater., 2017, vol. 141, pp. 129-32.

[26] M. Villa and M.A.J. Somers: Scr. Mater., 2018, vol. 142, pp. 46-49.

[27] Jae-hwa Lee, Takashi Fukuda, and Tomoyuki Kakeshita: Mater. Trans., 2008, vol. 49, pp. 193740.

[28] A Borgenstam and M Hillert: Acta Metall., 1997, vol. 45, pp. 651-62.

[29] M. Villa and M.A.J. Somers: in Int. Conf. Martensitic Transform., Aaron Stebner, ed., Chicago ( in Press), 2018.

[30] P. Wang, S. P. Lu, N. M. Xiao, D. Z. Li, and Y. Y. Li: Mater. Sci. Eng. A, 2010, vol. 527, 
pp. 3210-16.

2 [31] J. Van Den Broek, M. Goldschmitz, L. Karlsson, and S. Rigdal: Svetsaren, 2001, vol. 56, 3 pp. 42-46.

4 


\section{$1 \quad$ List of tables}

Table 1. Overview of materials, annealing parameters and testing procedures considered in previous works in order to test the thermal stability of reverted austenite in soft martensitic and supermartensitic stainless steels.

\section{Ref. Approx. composition [wt.\%] Annealing treatment $\quad$ Cryogenic treatment}

\begin{tabular}{llll}
\hline [6] Cr 13-16, Ni 5-6, Mo <1.5, C 0.03-0.06 & $860 \mathrm{~K}$ & $77 \mathrm{~K}$
\end{tabular}

\begin{tabular}{llll}
\hline [23] Cr 12-17, Ni 4-7, Mo <2.5, C $0.03 \quad$ Not specified & $77 \mathrm{~K}$
\end{tabular}

[5] Cr 15-17, Ni 4.5-6.5, Mo <2.9, C: $<0.07 \quad 870 \mathrm{~K} / 28.8 \mathrm{ks} \quad 77 \mathrm{~K}$

[11] Cr 12, Ni 5.4, Mo 0.5, C $0.028 \quad 870 \mathrm{~K} / 7.2 \mathrm{ks} \quad 271 \mathrm{~K}, 256 \mathrm{~K}, 248 \mathrm{~K}, 77 \mathrm{~K} / 72 \mathrm{ks}$

\begin{tabular}{llll}
\hline [21] Cr 12, Ni 6.5, Mo 2.5, C 0.01 & $910 \mathrm{~K}$ & $77 \mathrm{~K} / 3.6 \mathrm{ks}$
\end{tabular}

[10] Cr 12, Ni 4.4, Mo 0.5, C $0.07 \quad 870 \mathrm{~K} / 14.4 \mathrm{ks} \quad 4 \mathrm{~K}$

\begin{tabular}{llll}
\hline [22] & Cr 12, Ni 5.6, Mo 2.0, C 0.02 & $908 \mathrm{~K} / 14.4 \mathrm{ks}$ & $77 \mathrm{~K} / 72 \mathrm{ks}$
\end{tabular}


Table 2. Measured austenite fraction, $f_{\gamma}$, in vol.\% of differently annealed samples during or after applied thermal cycles in XRD or VSM

\begin{tabular}{cccccc} 
Thermal cycle & Method & $\boldsymbol{f}_{\boldsymbol{\gamma}}(\mathbf{8 7 3} \mathbf{K})$ & $\boldsymbol{f}_{\boldsymbol{\gamma}}(\mathbf{8 9 8} \mathbf{K})$ & $\boldsymbol{f}_{\boldsymbol{\gamma}}(\mathbf{9 2 3} \mathbf{K})$ & $\boldsymbol{f}_{\boldsymbol{\gamma}}(\mathbf{9 4 8} \mathbf{K})$ \\
\hline $\begin{array}{c}\text { Intercritical annealing } \\
\text { (maximum fraction during annealing) }\end{array}$ & XRD & 0.15 & 0.38 & 0.58 & 0.61 \\
\hline $\begin{array}{c}\text { Intercritical annealing } \\
\text { (retained fraction at room temperature) }\end{array}$ & XRD & 0.15 & 0.35 & 0.29 & 0.21 \\
\hline $\begin{array}{c}\text { Intercritical annealing } \\
\text { (retained fraction at room temperature) }\end{array}$ & VSM & 0.10 & 0.26 & 0.27 & 0.16 \\
\hline $\begin{array}{c}\text { Immersion in } N_{2} \\
\text { (retained fraction at room temperature) }\end{array}$ & VSM & 0.10 & 0.25 & 0.27 & 0.16 \\
\hline $\begin{array}{c}\text { Sub-zero treatment } \\
\text { (retained fraction at room temperature) }\end{array}$ & VSM & 0.10 & 0.23 & 0.22 & 0.15 \\
\hline
\end{tabular}




\section{List of figure captions}

2 Figure 1. Fraction of austenite $f_{\gamma}$ versus temperature $T$ for four inter-critical annealing treatments.

3 Numbers in the legend refer to the temperature reached during the heating step, immediately followed 4 by cooling.

5 Figure 2. Fraction of austenite $f_{\gamma}$ versus annealing temperature $T$. The three data sets refer to the 6 material before sub-zero Celsius treatment, after immersion in boiling $\mathrm{N}_{2}$ for $0.3 \mathrm{ks}$ and after additional 7 isothermal holding at $195 \mathrm{~K}$ for $15.3 \mathrm{ks}$.

8 Figure 3. Schematic Time-Temperature-Transformation, TTT, diagram for formation of lath martensite 9 from an approximate austenite fraction of 100 vol.\% (after [25]). The solid lines correspond to time10 temperature curves, starting from an initial temperature of $80 \mathrm{~K}$ and following linear heating rates, $11 \dot{T}_{a}>\dot{T}_{b}>\dot{T}_{c}$. The broken lines indicate constant fractions of transformed martensite, $\Delta f_{2}>\Delta f_{1}$, 12 during isothermal holding. The diagram demonstrates that up-quenching can prevent martensite 13 formation (following $\dot{T}_{a}$ ) and that the martensite content formed on reaching room temperature depends 14 on the heating rate (comparing $\dot{T}_{b}$ and $\dot{T}_{c}$ ).

15 Figure 4. VSM results from of sub-zero Celsius treatment: (a) Fraction of austenite, $f_{\gamma}$, of the 16 differently tempered samples vs. temperature for cooling to $195 \mathrm{~K}$ with $0.25 \mathrm{~K} . \mathrm{s}^{-1}$, isothermal holding

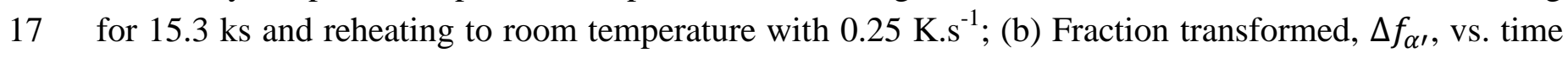
18 during isothermal holding at $195 \mathrm{~K}$. 